\title{
Escuela, cuerpo y milicia, historias de un redoble, de un simulacro que no termina ${ }^{1}$
}

\section{School, body and militia, stories of a frill; a simulation that doesn't stop}

\section{Escola, corpo e milícia, histórias de um rumor, de um simulacro que não termina}

\author{
William Moreno Gómez ${ }^{2}$
}

"cuando el hombre fuerte, armado, guarda su casa, lo que posee está en paz"

San Lucas, II, 14-28

\section{RESUMEN}

El artículo presenta un análisis de los intercambios sensibles que se proyectan, con relación a las prácticas educativas corporales, desde los discursos de apropiación e intervención para la conformación de niños y jóvenes escolarizados de Medellín en la primera mitad del siglo XX. Apelando a una matriz de análisis estética el autor se adentra, desde su lectura, en un proceso de significación, en contexto, de enunciaciones corporales allí contenidas sobre aspectos significativos de la conformación patriótica, moral e higiénica de los estudiantes.

Palabras clave: cuerpo; prácticas corporales; educación corporal; educación física; educación militar.

1. El presente artículo hace parte de la investigación "Recuperación de fuentes documentales para la Historia de las Prácticas pedagógicas del Cuerpo Escolarizado en la Primera Mitad del Siglo XX en Medellín", Universidad de Antioquia. CODI. 2008.

2. Profesor de la Universidad de Antioquia (Colombia).

3. Tomado del texto: La educación he ahi el problema, Rafael Bernal Jiménez (1933, p. 185). Pedagogo conservador impulsor de la Escuela Activa, de una educación defensiva y regeneradora. 


\begin{abstract}
This article presents an analysis about exchanges, which are projected, whit regard to educational corporal practices, from the speeches of ownership and intervention in order to the formation of children and young people from schools in the Medellin in the first half of twentieth century. Appealing on an array of aesthetics analysis, the author explores, from his reading, in a process of significance, in context, of the corporal statement contained there about significant aspects of the patriotic formation, moral, hygienic of the students.

Keywords: body; corporal practices; corporal education; phisycal education; military education.
\end{abstract}

\title{
Análisis sensibles de textos icónicos de la Educación Física en Medellín
}

Encontrar aproximaciones esclarecedoras a los problemas de la Educación Física impulsan este tipo de ejercicio que hoy me propongo desde una búsqueda de base histórica que inicia con un trabajo de rastreo del equipo de investigación. Bueno es reconocer, en lo personal, antes de dar el paso analítico, que esta aproximación va más del lado de las necesidades de explicarse devenires sociales, curriculares y pedagógicos de las intervenciones que hoy, con el cuerpo, en la escuela, en la ciudad, emprendemos los "trabajadores sociales". Los aportes de Mandoki (1994), Castañer (1996), Ibáñez (1986) y Létorneau (2007) invitan a una apropiación lectora de los enunciados corporales, apropiación de los decires y haceres de los hablantes desde los sub-mundos y tras-fondos, desde los pliegues y resquicios de los documentos iconográficos. Aproximarse a aquello que pasó allí, en el patio, en la escuela, en el ejercicio, en la marcha, en la intervención del cuerpo; esfuerzo que encamine al reconocimiento y hacemos con el cuerpo en la escuela y, posiblemente, como estrategia que permita proyectar las cosas que haríamos con el cuerpo en una educación planteada de otra manera. Retórica (lenguajes y paralenguajes), dramática (proxémica, cronémica y talante de lo motriz) se cruzan, a la manera de la sugerencia mandokiana (1994), para leer en los enunciados detenidos de un decir transcrito; hacer decir a textos que dan cuenta de la manera como se idearon, apropiaron y produjeron las estrategias de intervención corporal escolarizada por parte de los maestros de este país. Compartimos un presupuesto base: los enunciados que hablan de la educación corporal en Medellín entre 1900-1950 dan cuenta de los procesos de apropiación 
diferenciada (por los actores educativos) de discursos y prácticas, relacionados con la construcción de la subjetividad infantil; sugieren Saldarriaga y Sáenz (2007, p. 397) acción de poder que, dicen, se bate entre la producción de efectos homogenizantes e individualizantes. Desde allí, la historiografía descubre las cruzadas de higienización, moralización, civilización y normalización, los esfuerzos por la formación en el dominio de sí: virtuosos, dóciles, silenciosos, piadosos, o bien, según los ritmos y sentidos variables del orden social colombiano de los siglos XIX y XX, apuestas por la formación de sujetos activos, espontáneos, competidores, sanos, alegres, racionales, autónomos, críticos, solidarios.

\section{Las prácticas militares en los pliegues históricos escolares de la invención de la infancia en Colombia}

Las condiciones de configuración de las prácticas corporales militares o cuasi-militares en la educación gimnastica escolar, como parte esencial de la instrucción pública de la pobrería colombiana a lo largo del siglo XIX y primera mitad del siglo XX, son de diverso orden; entre ellas podrían considerarse:

\section{Sentido del acogimiento escolar granadino de la pobrería}

Recién lograda la independencia y bajo el temor de una arremetida española, se impone la idea bolivariano-santanderista (primeras décadas de siglo XIX) de consolidar un artefacto escolar (racionalismo) con capacidad para moralizar y disciplinar la pobrería granadina. En los interjuegos del poder pastoral y del poder civil y militar: recoger, "acuartelar", catequizar y normalizar constituyen la intencionalidad con-formativa de esta primera etapa de la instrucción granadina. Los partidarios del sistema lancasteriano lo alaban en función de lógica eficaz de operación e intervención que le acerca a la cinética y al pulso propio de las prácticas militares que según el pensamiento de los hombres de gobierno perfilan el tipo de hombre necesario con "aire de soldado" y capacidad combatiente; necesidades estas que interpretan un principio educativo de la época; se trata según el pedagogo francés R. Ambrosie (apud SALDARRIAGA; SÁENZ, 2007, p. 399) de "someter a los niños a una regularidad, a una serie de movimientos que hacen de una multitud un solo individuo obediente a una misma voluntad [...]". En la sumisión individual y la obediencia automatizada la clave de la economía corporal lancasteriana (1.000 alumnos por 1 maestro); el régimen cuasi-militar de administración corporal acerca las matrices sociales escuela y milicia. Para 
tal empresa, una instrucción corporal cuasi-militar para la cual se dijo, en la época, quienes mejor estaban preparados eran los oficiales del ejército.

\section{La emulación y el "honor" en el modelo de enseñanza simultanea}

Se evidencia el talante emulacionista, ordenador y heroicista de los apropiadores de la pedagogía pestalozziana de fines del siglo XIX. En el país se desarrolla el método pestalozziano promovido por los liberales radicales ${ }^{4}$ que desde el poder inician una cruzada educativa (formación de maestros) de la mano de la misión de los pedagogos alemanes ${ }^{5}$. De origen protestante, estos promotores traídos desde Alemania, "cruzados de la ilustración y la modernidad", encuentran fuerte resistencia en el gobierno conservador de Antioquia y en su aliado, la iglesia católica. Este sistema de enseñanza (simultáneo) es denominado por algunos como modelo de las congregaciones católicas. La uniformidad, el autoritarismo, la continuidad de las herencias lancasterianas de quietud y orden (según evidencian las críticas de los pedagogos liberales promotores del modelo activo) crean, posiblemente, condiciones favorables para la permanencia de las prácticas cuasi-militares en el campo de las prácticas escolares. Después de la guerra con el Perú, y ante los discursos preventivos de los nacionalistas, mediante Decreto 1734 de 1933 se establece la obligatoriedad de la Educación Física. Los referentes de la "disciplina del honor" y el sistema de premios y castigos, el control de las "bajas pasiones", las referencias heroicistas y patrióticas (ver Sáenz; Saldarriaga, 2007, p. 402) pudieron definir un espacio para comprender el "valor pedagógico" de estas prácticas disciplinarias extremas. Se impone a través de ellas un efecto educativo homogeneizante. Boy Scouts, exploradores, marchas religiosas y actos cívico-patrióticos se suman a la tarea educativoevangelizadora y educativo-regeneradora de niños y jóvenes.

4. La historiografía militar colombiana registra que los románticos liberales de 1850 miraban al ejército como una institución inútil y amenazante para las libertades civiles.

5. Expertos en la lucha cultural prusiana... se dice que allí la guerra se gano desde las Escuelas Normales. 


\section{Connivencia sospechosa de la "perspectiva prusiana" y la pedagogía activa}

En las últimas década del siglo XIX, a partir de la apropiación de los aportes de Decroly, se desarrolla una perspectiva natural-experimentalista y fisiologista (psico-médica). En las primeras décadas del siglo XX como nueva educación se configura una pedagogía liberal-conservadora de "sana convivencia" que luego, cuando llegan los liberales al poder (tercera y cuarta década), bajo la influencia de los postulados deweianos, se despliega como Pedagogía de la socialidad liberal. Este periodo define una pragmática y una economía corporal ${ }^{6}$ que marca los discursos y las prácticas escolares de la Escuela activa que contempla (consolida) las prácticas gimnasticas y deportivas en función de la formación del talante social de los educandos. Para los historiadores de la educación física colombiana este periodo marca significativamente el nacimiento, como tal, de la E.F. en nuestro país. Al parecer estas prácticas escolares "modernas" no superan las viejas prácticas cuasi-militares, las acogen, conviven con ellas. En la entrada al siglo XX, Loaiza (2007, p. 78) evidencia la coexistencia de la instrucción militar con las excursiones semanales, dice que unas y otras ocupan un lugar preponderante en el calendario del año escolar. Esta connivencia, entre una perspectiva activa y otra cerrada, puede ser explicable desde varios lugares. Los pedagogos alemanes vienen de una experiencia "libertaria" que se basa en los apoyos de los "batallones escolares"; en la escuela prusiana las prácticas militares son la base de su educación corporal y pasaporte definitivo a la libertad y a la unidad nacional; el país se encuentra inmerso en un ambiente guerrerista (conflictos iglesia-estado, conflictos partidarios, etc.), ambiente muy proclive al afianzamiento del "espíritu militar". La dirigencia antioqueña explaya su "pragmatismo" social, político y económico hacia los terrenos de la instrucción pública; según Cano (2007, p. 73), bajo el control conservador se mezcla “[...] en su sistema de instrucción pública: la difusión del método pestalozziano (de los pedagogos protestantes), la adaptación del reglamento de los Hermanos de las escuelas cristianas y (las) clases de instrucción militar en (las) que se aplicaba con entusiasmo la disciplina moderna del ejercito del Imperio Alemán”. 


\section{La implementación regeneracionista de las "prácticas duras"}

Perfilados por la experiencia política decimonónica de prevalencia militarista/guerrerista, las dictaduras visibles u ocultas (con sus "juegos de guerra") campean de México hasta la Patagonia. En Colombia, a lo largo de las primeras décadas del siglo XX: el fantasma de la guerra y del pecado, los determinantes regenerativos (de prevalencia en las primeras tres décadas) y de las ilusiones gubernamentales con la regulación y el acompasamiento social (presentes después de las primeras tres décadas) alimentan la intervención social por medio de vigorización y virilización, entre ellas la educación pre-militar (en sus formas "primitivas" y "cultas"). En las primeras tres décadas del siglo XX, al lado del discurso médico que quiere prevalecer en el ámbito escolar ${ }^{7}$, se impone la estrategia de llevar a la escuela "prácticas duras" (fuerza, vigor, virilidad, resistencia a la fatiga y al dolor, etc.), que ayuden a contrarrestar el carácter y la naturaleza "blanda", frágil, "pisaverde", ociosa, enfermiza y salvaje de los hijos del trópico ${ }^{8}$. La regeneración está en boca de todas las autoridades; en el discurso de los militares Cortez y Rojas a los participantes de la gran excursión de 1925 convergen los discursos "naturalistas", regeneradores y patrióticos (ver Barbosa, 1926, p. 158). El apoyo mancomunado de militares, comerciantes, banqueros, políticos, damas prestantes, médicos y Cruz Roja configuran una "excursión físico científica" nunca antes vista. El problema de la "cultura aldeana" o de la cultura nacional" es de todos. Los discursos heroicistas en boca de los generales ${ }^{9}$ anuncian a los niños sobre el sentido patriótico de la experiencia; explican desde la gran tribuna el significado que poseen los grandes héroes militares para la juventud colombiana, el sentido del sufrimiento, de la fatiga, del dolor, de la inmolación, de la muerte heroica, de la sangre derramada por los grandes ideales. El sentido "defensivo" de la cultura y la educación física se apoya en los presupuestos de la moralización, la regeneración de la raza y la necesaria preparación de la reserva militar de la patria. A viva voz, les predicaba el general desde el balcón a los 10.000 niños que logran movilizar: "La vida de Sucre es para vosotros, oh niños que me oís, el mejor y más fecundo ejemplo. Puro y casto como un San Luis de Gonzaga, sus virtudes se aquilataron día a día, sin

7. El médico tuvo asiento en las comisiones seleccionadoras del profesorado para la educación física.

8. En 1923 en la revista del ejercito (Cultura Física, p. 130, Bogotá) califica de "tendencia altamente loable" esto de incluir la gimnasia en el pensum y se ensalza el hecho de ser asignada (como materia obligatoria) a los oficiales del ejército, es a ellos a quienes se les considera con la mejor preparación para tal empeño.

9. Ver discurso de los coroneles Carlos Cortez Vargas y Efraín Rojas a los participantes de la gran excursión en "La Gran Excursión escolar de 1925", en Barbosa (1925, p. 158). 
contrastar con el coraje y la energía propias de un gran capitán: Copo de nieve sobre un charco de sangre, lo define un notable escritor contemporáneo [...]". Estas prédicas identifican una léxica heroicista y militarista que ha acompañado durante estos doscientos años, desde el ejercicio sensible en los actos cívicos, la configuración de nación y ciudadanía. En aquel momento la presencia y los discursos de los Caballero y los Lleras (gente portadora de aires pedagógicos renovadores) sonarían débiles y minoritarios ante los discursos pastorales y militares; allí al lado de la sensibilidad "natural", se cocinaba también, de la mano de los representantes del poder político y militar, una sensibilidad patriótica. El ejercito, según el cronista, "comprendió desde un principio el valor educativo de la excursión, fue para ella (un) poderoso auxiliar" (BARBOSA, 1926, p. 9).

\section{La matriz escolar y la matriz militar en el desarrollo de la cultura fisica}

En Colombia, aunque no con tanta fuerza como en Brasil y Chile donde los orígenes mismos de las instituciones formadoras de los profesionales del área están muy emparentadas con las fuerzas militares, se evidencia una clara influencia de las directrices militares en el desarrollo de las clases de gimnasia escolar, en las prácticas de la educación física y en el desarrollo del deporte competitivo. A las misiones europeas ${ }^{10}$ y chilenas, llegadas desde las últimas décadas del siglo XIX y a lo largo de la primera mitad del siglo XX, no les es extraña a la influencia militar; los ecos de las gimnasiadas y revistas nacionalsocialistas alemanas, españolas e italianas con sus respectivas preparaciones desde los juegos militares debieron calar en la sensibilidad nacionalista regeneracionista criolla. La lucha por la limpieza de la raza desde las prácticas corporales no se reducía a una estrategia local. Es evidente a lo largo de este periodo el recurso a militares porque es la práctica militar ${ }^{11}$ la que llena la expectativa a la representación que se tiene sobre lo que debe ser la "educación gimnastica". Ellos constituyen la base profesional del área, suplien la falta de un profesorado capacitado para servir la educación física escolar ${ }^{12}$. Es evidente que de las prácticas militares "primitivas" a las prácticas "militares cultas y distinguidas" de

10. La última misión alemana (años sesenta y setenta del siglo $\mathrm{XX}$ ) da origen a los nuevos institutos y escuelas de formación de los profesionales del área (Lima, Quito, Medellín, Cali). Ya en 1925 se habían dado los primeros pasos para la creación del INEF y de una comisión nacional que promoviera la Cultura Física. En 1936 se oficializaba el INEF en Bogotá.

11. El plan de estudios expresado en el Decreto 670 de 25 de junio de 1912 (Sobre Escuelas Normales) tiene en los cinco años de educación elemental tres horas semana para lo que allí se denomina "ejercicios militares".

12. Decreto 850 de 24 de septiembre de 1910: "además de las clases de los cursos académicos hay clases $[\ldots]$ piano o solfeo $[\ldots]$ gimnasia y ejercicios militares dirigidos por oficiales instructores del Regimiento [...]”. 
los colegios de las congregaciones, a donde va la "clase prestante", la de la alta esfera de la ciudad, hay una gran diferencia. Mientras los lasallistas practican esgrima y boxeo francés con armas y uniformes importados, los chicos de las anexas normales marchan descalzos armados de fusiles de palo.

Parece que un protocolo y una disciplina escolar que se apoyan en una metódica de ejercicios cuasi-militares constituyen éticas, estéticas y políticas que desde finales del siglo XIX aportan significativamente a la con-formación de un "modo de ser corporal", constituyéndose en eje considerable en el proceso de constitución de la infancia. Voces tímidas y minoritarias como las de algunos graduandos medellinitas de la escuela normal en los años cuarenta se harán escuchar tratando de cambiar el rumbo a punta de desmemoria: "A nosotros los colombianos, que por espíritu y naturaleza somos netamente demócratas, nos corresponde formar verdaderos ciudadanos, y no militares" (MEJÍA, 1942, p. 44). Los aires refrescantes de la corriente deweina, tan sentida, según la historiografía educativa colombiana, entre la tercera y cuarta década del siglo XX, debió empezar a marcar un esculcamiento a estas "prácticas no civilizadas" tan emparentadas con la fuerza y la educación de los viejos tiempos. De la mano de los pedagogos liberales secularistas se abren nuevos panoramas críticos y explicativos. Es paradójico, el año 1925, ya en las postrimerías de la "hegemonía conservadora", constituye un momento histórico muy significativo para la educación física colombiana. Ese año se expide la ley 80 (considerada la carta magna de la educación física); se impulsan las plazas de deporte y la planeación local y nacional, la formación del profesorado de la mano de misioneros alemanes ${ }^{13}$, diseña el proyecto de un Instituto de Gimnasia; ideas revolucionarias para el área que esperarán la llegada de los gobiernos liberales de Olaya y Santos y López Pumarejo para poder desplegarse. En Colombia se cambia, en alguna medida, la estrategia central de la construcción de la masculinidad; el deporte toma un lugar significativo en los dispositivos que encaminan a la con-formación del hombre moderno. Hasta ese momento las ideas de la templanza, la castidad, la victoria sobre las pasiones, el estimulo de las facultades y el disciplinamiento moral y patriótico encontraron en el redoble cuasi-militar un tono para la con-formación escolar de niños y jóvenes. Si se siguen los estudios de Devís (1994), Barbero (1995), Rodríguez (2003), García et al. (2002), Kirk (1993), Engaña (2000) y Planella (1995) entre otros, se podrá observar como la pedagogía cuasi-militar, a través de la educación física, a pesar de las resistencias de algunos, está presente en la cotidianeidad educativa entre inicios de mitad del siglo XIX y mitad del siglo XX. Las revistas gimnasticas, las excursiones escolares, los boy scout, las tardes cívicas, las interminables izadas de bandera o las marchas militares

13. El gobierno central contrata a través de la misión pedagógica alemana al profesor Hans Hubers, experto deportivo. 
en plazas y calles de pueblos y ciudades al ritmo de las bandas marciales, los desarrollos de los torneos y una instrucción deportiva escolar metódica son prueba fehaciente de ello. No hay que olvidar que los estados nacionales han sido, en algún momento de su proceso constitutivo, impulsores de primer orden de la gimnastica escolar y que, en esos procesos, esta práctica, de la mano de las estrategias militaristas o de las dictaduras militares, explicitas o implícitas, sin fronteras espaciales o temporales, han devenido en dispositivos de preparación pre-militar. Las prácticas pre-militares y deportivas han significado un medio muy importante para la conformación de un "musculo de guerra y de trabajo" y de una actitud subalterna y normalizada de la población escolarizada.

\section{Cuatro registros icónicos para aproximaciones analisticas prosai- cas a los discursos de la educación corporal en Medellín de prime- ra mitad del siglo $\mathrm{XX}$}

Los textos sobre los discursos de la educación corporal de primera mitad del siglo XX, encontrados en nuestra investigación en la ciudad de Medellín, permiten identificar registros históricos que dan cuenta de la apropiación pedagógica que hicieron nuestros maestros y maestras. Se dejan leer los enunciados que reflejan la forma como volcaban retóricamente estas adquisiciones hacia las prácticas corporales escolares. Tomando estos enunciados como textos iconográficos, ayudados por la matriz de análisis estético de Katya Mandoki (GARCÍA, 2007) o con matriz de análisis modificada en Moreno (2005; 2007) hemos emprendido lecturas de textos que reflejan los procesos de intervención corporal en las instituciones educativas de nuestra ciudad durante el siglo XIX; con este trabajo empezamos a introducirnos comprensivamente en el análisis sensible de los discursos corporales del siglo XX.

\section{Espacio del geómetra}

La gimnasia sueca es de las más eficaces en sus resultados, (ella) marca la etapa moderna de la educación física. El sistema sueco además de tener la enorme ventaja de ser racional, presenta la de estar basado en principios fisiológicos, biológicos y psíquicos [...] (MEJÍA, 1942).

Entre las objeciones que al sistema de gimnasia (sueco) pueden hacerse, está como principal la de ser fastidioso. Es un hecho real, que una serie de ejercicios que como el sistema sueco se ejecutan sin más contemplación 
y por más de veinte minutos hastían al niño con alguna facilidad, por la monotonía de su ejecución, por la fatiga que como consecuencia hace experimentar al niño [...] el carácter rígido y seco [...] razones que explican el por qué este sistema es víctima del hastió del niño (MEJÍA, 1942). Fotografia "Haciendo Gimnasia Sueca en el patio de la Normal 1930-1940 (ARCHIVO Histórico Escuela Normal Superior de Medellín).

La masa de niños ocupa el espacio (densidad) en razón de la operación y la designación del geómetra corpo-espacial. Hay una jerarquía establecida en razón de la clasificación escolar, los "chiquitos" de la mano del monitor (herencia de la educación mutua) y los grandes de la mano del "Sargento" (proxémica). Él, está en el límite, en la frontera, de reojo vigila al aprendiz y sus "querubines", mientras, los "piernipeludos" intentan, movidos a grito del "Sargento" (acústica), coger ritmo (cinética); Él, pretende que todos lo hagan igual (pulso)... la individuación de Rosseau se apropia en homogenización por masificación y racionalización; es posible, aún, por fuera de ese tiempo (cronémica), que alguien se pregunte por qué, y para qué todo ese martirio. Preguntándose sobre ¿qué estética se funda sobre la uniformidad y la homogenización corporal? Una posible respuesta: la sociedad impone sus fines a la escuela. El sol calienta el empedrado y según la sombra de los cuerpos el calor es insoportable (el cuerpo se somete a prácticas dolorosas, la educación física apunta a la templanza... los chicos aguantan (rigidos), seguramente más de uno, acalambrado, maldice entre dientes (quinésica). La formación es en pirámide (proxémia), los que flaquean o se equivocan van para la cola (atrás), adelante están los más fuertes, los modelos, los referentes, los acompasados (clasificación), componen la elite a emular. Modernidad y racionalidad corporal, acompasamiento y regulación; se ensaya una práctica que marca ritmo de gobierno. La biopolítica gobierna bajo los principios disciplinarios. El discurso de apropiación del normalista Martin Ramiro Mejía lleva la semilla de la Escuela Nueva; el "interés", la consideración del educando, cuestiona la rigidez y el mecanicismo corporal sueco. La monotonía en la ejecución no interesa a los hijos de Decroly, Dewey y Montesori, la escuela se desea como territorio amable para el desarrollo del niño, lugar interesante e interesado en la formación de ciudadanos útiles, sanos, productivos, sociables y civilizados. 


\section{Los desfiles patrióticos... formando varones egregios...}

Hoy con hermoso desfile de comunidades estudiantiles que regaron coronas al pie del monumento de un joven héroe, se conmemoró en Medellín el histórico acontecimiento de la batalla del Bárbula y del glorioso sacrificio de Atanasio Girardot, hijo preclaro de la ciudad. Nada nos parece tan propio para educar al pueblo, como esas fiestas conmemorativas de algún episodio de nuestra guerra de Independencia, en que se exhiben en ordenada formación los jóvenes de los Colegios y los niños de las Escuelas. Allí, obligados siquiera, aprenden a respetarse a sí mismos, a ver en esas comunidades de chiquillos, una cosa seria y grande, y a tributar a la sociedad los homenajes que siempre han creído deberle las personas cultas y bien nacidas; como también a descubrirse reverentes ante las estatuas, bustos y retratos de varones egregios que, con sus grandes hechos, han ilustrado a la Patria. Seguramente después de que los escolares y universitarios recorrieron en prolongadas filas, varias de las calles de la ciudad; después de que se detuvieron con religioso silencio delante del monumento que conmemora algún hecho grandioso o heroico; después de que vieron que venerables ancianos, o comerciantes acaudalados, o sabios reconocidos como tales se descubrieron reverentes y con el mayor comedimiento al escuchar las primeras notas del Himno Nacional; después de que esto se repita por cuatro o más veces, seguramente no se volverán a presenciar esas tumultuosas salidas de los establecimientos, con bullas enfadosas, ni se oirán las palabras de taberna con que algunos estudiantes pretenden hacerse notables, ultrajando con increíble atrevimiento a las señoras y a los ancianos; y ese acatamiento que acabará por convertirse en hábito, hará que podamos vivir en verdadera sociedad. Aprovechen los Maestros estas fechas en que se recuerdan las grandes pruebas de patriotismo desinteresado que dieron los héroes de la Magna Guerra (ESTUDIOS Pedagógicos..., 1913).

Comunidades estudiantiles, de chiquillos, escuelas, colegios y universidades (escenarios), todos en ordenadas formaciones (proxémica), en prolongadas filas (volumen de la acción motriz), obligados en religiosos silencio (acústica y peso de la matriz religiosa) a descubrirse reverentes (quinésica de consentimiento), entre acaudalados y sabios reconocidos, varones egregios (léxica proxémica de clase y de género) ante los signos guerreros - Girardot, Bárbula, Himno Nacional (iconos heroizadores) -, evocación de los gloriosos sacrificios y del patriotismo desinteresado, remedio pedagógico contra las bullas enfadosas y las palabras de taberna (léxica y proxémica de clase, condena de lo popular), acatamientos (quinésica del consentimiento) que se convierten a base de repetición - mínimo cuatro veces (frecuencia de la acción motriz) - en hábitos de la "verdadera sociedad" (dirección 
motriz), la de los bien nacidos (proxémica filial de clase). Los cuerpos se disponen, filados, ordenados, silenciados, obligados; se contrarresta el tumulto y el bullicio enfadoso. La ciudad se informa, son recorridas (cinética) sus calles por el remolino civilizador (pulso); la educación del pueblo se juega en la fiesta patria. Es tiempo de descubrirse en marcha (quinésica) ante los iconos homogeneizadores; en la evocación de los "gloriosos sacrificios" la unión en la sangre. La heroización, así como la ejemplarización a partir de la géstica reverente de los "bien nacidos", opera como dispositivos con-formadores. La matriz cívica, militar, religiosa y escolar se encuentra en el acontecimiento, en el pastiche social; la instalación ritual tiene la fuerza de la ofrenda-clase, se riegan las coronas, se siembran a fuerza del control corporal las semillas de una ciudadanía ordenada, reverente, acallada, desatrevida (cinética del dominio). Hay una decisión tomada evidenciada en el deseo con-formador: "obligados siquiera" a reverenciar y a descubrirse; no hay obstáculos para la dirección conformativa como no hay obstáculo para la edad de la inmolación patriótica "joven héroe", ni para el talante de los sacrificios "gloriosos" referentes para la educación de un pueblo que debe poner la vida misma al servicio de los "deberes superiores". La fila, deseada, silenciosa, define una formación prolongada que se apodera de la ciudad; en ella, en la uniformidad, máxima expresión de poder sobre el cuerpo, se funden los hombres en un solo compas, aquí desaparece toda diferencia. El paso está marcado por una cinética sumada, acumulada y controlada. Los venerables, los comerciantes y los sabios, los de la esfera elevada, buscan un pretexto heroico que les reúna; modelativos, ante la masa tumultuosa y enfadosa, necesitada de "civilización", los venerados y los venerables referentes de la "cultura culta" enseñan, conforman.

\section{Soldados para nuestra hambre de conquista}

EL ESPECTADOR ha lanzado la idea de que se establezcan en Antioquia los Boy Scouts como medio de educación física, idea que en nuestro sentir debe acogerse con entusiasmo, por consultar las necesidades actuales de la sociedad. En la guerra del transvaal un general ingles se vio precisado a emplear niños en una exploración militar y de aquí el que Inglaterra fundara los Boy Scouts, es decir, asociaciones de muchachos exploradores. Entre los medios exagógicos de educación física se cuenta en primera línea el movimiento, el cual, para que tenga finalidades educadoras, debe ser proporcionado al desarrollo del niño, armónico e interesante, condiciones que llenan superabundantemente los Boy Scouts [...] La sabiduría helénica, tan repudiada por algunos pseudo sabios, torna a brillar en pleno siglo veinte. ¡Gloria y ventura al barco portador de lo grande y de lo bello! Nada más de acuerdo con las condiciones étnicas de nuestro pueblo que la justificación de 
centros escolares donde se explote y regularice nuestra expansibilidad y sed de campo de acción a nuestra hambre de conquista. Vivimos en los trópicos; la sangre arde en las arterias y baña con ímpetu nuestro cerebro; sentimos necesidad de movimiento y de acción; estamos estrechos en el cortijo patrio; los terrenos de Antioquia, pobres en capas vegetales, no corresponden al trabajo; fuerza es que aspiremos a rebasar los límites de nuestra heredad; la integridad nacional pide que estemos apercibidos para la lucha, como aquellos hijos de Israel que con una mano vibraban la espada y con la otra coacervaban los materiales para su templo; luego nuestra educación debe llevar fines variados y complejos. Atenas con la gimnasia atendía, como a fin único, al embellecimiento del cuerpo; Esparta formaba atletas para la guerra, como más tarde lo hizo Roma. Colombia debe apetecer ambos fines: educar caballeros y soldados (EDUCACIÓN NUEVA, 1913).

A principios del siglo XX el peso de los motivadores instruccionales decimonónicos (cronémica) pesan demasiado (tono, volumen); con ellos se las tienen que ver los aires renovadores de la Escuela Nueva (icono). Las estrategias escolares y no escolares (escultismo, excursionismo), gimnasia pedagógica, enseñanza de milicia que apunta a viejos objetivos articulados a los intereses pastorales - atletas de dios - y estatales - atletas de la patria - (proxémica de poder). Las estigmatizaciones étnicas sirven de acicate para reclamar una instrucción comprometida con los despliegues políticos apropiativos: expansibilidad y hambre de conquista (uso social del espacio). Estrecho y estéril el cortijo patrio, no queda más que el rebasamiento del límite (uso social del espacio) y para ello se requieren soldados, una educación que instruya para la lucha, para la ocupación (uso social del espacio). En el cuerpo, con una mano, haciendo templo, y, con la otra, a nombre de la integridad nacional, a punta de espada, contra lo otro y contra los otros, haciendo patria. Proxémica corporal, cuerpo y poder, usos corporales y apropiaciones de poder sobre el cuerpo. A ello se le denominaba necesidades de la sociedad. El escultismo nace de un uso militar de los niños ingleses; exploración, movimiento, acción, armas, guerra, vigor, lucha, disputa, conquista, referentes para formar los atletas que requiere lo social hegemónico. Antecedentes del involucramiento histórico forzado, de no acabar ${ }^{14}$, de los niños en la guerra.

14. En junio de 2003, la Coalición contra la vinculación de niños, niñas y jóvenes al conflicto armado concluyó que "en el contexto del conflicto armado colombiano, los niños y jóvenes son una y otra vez víctimas de crímenes de guerra y de lesa humanidad". El reclutamiento de niños y jóvenes es una constante en estos doscientos años de historia. Entre 11.000 y 14.000 niños y niñas están vinculados al conflicto armado; hay registros que muestran como los niños campesinos, indígenas y afro-colombianos son las víctimas más frecuentes del reclutamiento. Según Human Rights al menos uno de cada cuatro combatientes irregulares de la guerra civil colombiana es menor de 18 años, la mayoría proceden de familias pobres. 


\title{
El toque de clarín moviliza la avanzada higiénico-patriótica
}

\begin{abstract}
No puede ser indiferente a la educación cuanto afecte los intereses vitales de la nacionalidad, porque, en el estado actual del mundo y mientras el ideal de una humanidad nueva no vaya a convertir en un hecho social y jurídico la abolición de las fronteras de los Estados, el concepto de nación y de patria continuarán constituyendo uno de los más poderosos y sagrados resortes del engrandecimiento de los pueblos. Aceptamos el principio de que la escuela debe participar intensamente en la gran obra del desarme de los espíritus, en que se hallan empeñados en el mundo entero generosos apóstoles y nobles pensadores; pero de ahí a renunciar al concepto de patria y con él a toda la grave serie de consecuencias que se deducen de la defensa nacional, existe un abismo inmenso. No fundamos esta afirmación en lo que podría llamarse el hábito mental nacionalista transmitido por una especie de "consuetudine" a través de una larga serie de generaciones; la basamos, con tristeza, sobre un hecho histórico fundamental, en una ley inmanente del linaje humano: la guerra es el estado natural del hombre; la paz permanente es un fenómeno que no puede considerarse sino dentro del campo deontológico, dentro de lo que debería ser, pero cuya realización es superior al esfuerzo humano (BERNAL, 1949, p. 185).
\end{abstract}

Los discursos "defensivos ${ }^{15}$ (léxica guerrera)" de Rafael Bernal Jiménez llegan entre segunda y tercera década del siglo XX a nuestras escuelas normales, en los archivos de la Normal Superior de Medellín se puede constatar la presencia de sus textos, y lo más interesante para nuestros estudios, la forma, como en los discursos (tesis) de los estudiantes normalistas se da esta doble apropiación interna de un dispositivo nacional e internacional de intervención

15. Hacen parte de un dispositivo higiénico identificable en la primera mitad del siglo XX; operación que orienta la política del poder para la regeneración de la población pobre colombiana de cara al espíritu modernizador. Educación que apunta a dotar al pobre de "resistencias" contra los lastres físicos, degenerativos y hereditarios. Dos estrategias le componen: La "escuela del examen", que basa su acción en los registros, las observaciones, mediciones y clasificaciones de los cuerpos, escuela donde médicos y maestros a base de estadística "a la manera europea" controlan los cuerpos. En Antioquia es paradigmática la labor del médico escolar (es el caso del doctor Vasco) a punta de test, curare y electrochoques, de la mano del maestro desarrolla una campaña "restauradora". La "escuela defensiva", la escuela "a la medida del país", autóctona y defensiva antes que constructiva. Educación para la regulación de los procesos biológicos de la raza; pedagogía para la restauración fisiológica (regeneracionismo). Para ello una política y una práctica alimentaria subsidiada al lado de ejercitaciones, juegos y excursionismo escolar. Dos formas de caracterización histórico discursiva de las estrategias de intervención social y educativa de la población infantil (Véase Sáenz; Saldarriaga; Ospina, 1997, p. 77 apud Noguera, 2003, p. 187). 
social y pedagógica de la ciudad, de la infancia en ella (pulso concéntrico). Allí los aportes para la configuración de un discurso de la educación corporal en nuestra región. Los discursos de la cultura física, de una educación del cuerpo se configuran de la mano de los discursos de lo moderno y de la modernización que se impulsa en Colombia desde los años veinte (ver Espina, 2006, p. 56). Se trataba de cultivar el cuerpo moral y físicamente. El cuerpo, allí, a diferencia de lo que se ha creido, estaba en primera línea. El debate eugenésico como consecuencia de las orientaciones de la Conferencia Panamericana de higiene de 1926, expresión del poder bio-político continentalizado, toma cuerpo en los discursos y las prácticas de la intervención social y corporal del cuerpo; allí el debate de la cultura física dio contexto a lo que se convirtió en estrategia gubernamental para la con-formación de la infancia. La marcha, el redoble y el toque de los clarines muestran el contexto de la naciente "escuela nueva" y en la perspectiva de la escuela defensiva, un norte; el invasor, frente al que hay que prepararse tiene varias caras. El invasor externo que pasa de las ambiciones realistas a las ambiciones territoriales regionales (proxémia) o a los fantasmas de los ejércitos de virus, bacterias y demonios de pobreza y primitivismo tropical (iconos). El deterioro biológico, la defensa de la patria, la productividad, la "entereza moral religiosa", el progreso y la civilidad conforman los referentes centrales del discurso pedagógico de los reformadores educativos en el contexto de una gobernabilidad liberal-conservadora que se declara adalid de la Raza. Según Espinal (2006, p. 56), en Medellín, en las postrimerías de la primera mitad del siglo XX, se crea un dispositivo gubernamental para la gestión higiénica; por Acuerdo Municipal se crea la dirección higiénica. Enfermedad, seguridad, educación, nutrición y saneamiento urbano configuran la base referencial sobre la que se constituye la cultura educativa de una ciudad que se inscribe, por lo menos, retóricamente, en la dinámica modernizadora. La regulación social dispone de la cultura física como dimensión de un discurso purificador, que no sólo se reduce a los anhelos eclesiales explícitos.

\section{A manera de conclusiones}

Los registros existentes en nuestro archivo patrimonial sobre los discursos de la educación corporal de Medellín de primera mitad del siglo veinte dejan leer:

- en los planes de estudio de Educación Física y en el currículo de las instituciones formadoras de maestros, la configuración discursiva de la cultura física como base de una naciente disciplina escolar que se hace un lugar entre las disciplinas académicas, pedagógicas y utilitarias (ramo que se inscribe de cara a su proceso de legitimación en 
la retorica moderna y modernizadora de nuestro país);

- la connivencia de las viejas prácticas cuasi-militares de la instrucción pública decimonónica con las prácticas corporales promovidas por la escuela nueva;

- la utilización patriótica, heroicista y pastoral de las prácticas educativas lúdicas del "naturalismo reformista"; allí la exaltación y las idealizaciones pastorales y bélico-militaristas de los generales;

- la reconfiguración de las prácticas de intervención pedagógica de lo corporal en las estrategias y dispositivos de los anhelos modernizadores (virtud, higiene, civilidad, productividad) de la clase que detentaba el poder;

- la actualización de las prácticas gimnasticas y deportivas europeas en forma diferenciada hacia los colegios privados y las escuelas públicas;

- los procesos embrionarios de crítica local (década de los treinta y cuarenta) a las gimnasias rígidas y coreográficas de origen europeo unidas al interés por los idearios pedagógico-corporales de los inspiradores de la Escuela Nueva en Colombia (Decroly, Dewey, Montesori, etc.);

- la configuración de las prácticas corporales escolares como estrategia "dura" para la con-formación ciudadana (estrategia eugenésica);

- la utilización de la intervención corporal como estrategia convergente en la acción medico-pedagógica sobre los cuerpos por parte de la estrategia "escuela del examen" y "escuela defensiva".

Seamos firmes y constantes en la labor que ha de producir algún bien para la familia, la patria, y la sociedad. La lucha es de los valientes, y la gloria sólo se recibe después de la fatiga y el combate (ANÓNIMO apud CARDONA, Arturo. Tesis - Escuela Normal Superior de Medellín, f. 1, 1939).

\section{REFERENCIAS}

BARBERO, J. I. La Educación Física en España (Una aproximación genealógica). Instituto Andaluz del Deporte., p. 29-42. In: AAVV Unisport: El deporte hacia el Siglo XXI. Málaga, 1991. 
BARBOSA, F. J. La gran excursión escolar de 1925. Sus antecedentes y su desarrollo. Bogotá: Editorial Manrique, 1926.

BERNAL, R. La educación: he ahí el problema. Bogotá: Ministerio de Educación Nacional, 1949.

CASTAÑER, M. El cuerpo: gesto y mensajero-verbal. In: Tándem, 3, p. 39-49, 2001.

1996.

. Pedagogía del gest i missatge no verbal. Lérida: Arts Gràfiques Bobalà,

CONTECHA, L. F. La educación física y el deporte en Colombia. Una historia. In: Revista Digital Lecturas: Educación física y deportes, año 4, n. 17, Buenos Aires, 1999. Disponible en: <http://www.efdeportes.com>.

DEVÍS, J. Educación Física y desarrollo del curriculum. Tesis doctoral - Universidad de Valencia, 1994.

ESPINAL, C. E. Cuerpo civil, controles y regulaciones. Medellín: Fondo editorial Universidad de EAFIT, 2006.

GARCÍA, C. et al. Discursos de la Educación Física (del Siglo XIX en Medellín). Universidad de Antioquia, 2002.

HERRERA, X. Las prácticas corporales y la educación Física en la escuela primaria entre 1870 y 1913. Revista Lúdica Pedagógica. Bogotá, n. 4, jul. 2000. Disponible en: http://www.pedagogica.edu.co/w3/storage/lud/articulos/lud04_04arti.pdf. Acceso en: 23/03/2009.

IBÁÑEZ, J. Más allá de la sociología. El grupo de discusión: teoría y crítica. Madrid: Siglo XXI, 1986.

KIRK, D.; TWIGG, K. The militarización of school physical training in Australis: the rice and demise of the Junior Cadet Training Scheme 1911-31. History of Education, v. 22 , n. 4, p. 391-414, 1993.

LOAIZA, G. El maestro de escuela o el ideal liberal de ciudadano en la reforma educativa de 1870, Historia crítica, Bogotá, p. 62-91, 2007.

LORETO, E. M. La escuela primaria popular en el siglo XIX en Chile. Reconstrucción del espacio escolar. Programa Interdisciplinario de Investigaciones en Educación, Santiago de Chile: PIIE, 2000.

MANDOKI, K. Prosaica. Introducción a la estética de lo cotidiano. México: Grijalbo, 1994. 
NOGUERA, C. E. Medicina y política. Medellín: Fondo editorial Universidad de EAFIT, 2003.

SÁENZ, J.; SALDARRIAGA, O.; OSPINA, A. Mirar la infancia: pedagogía, moral y modernidad en Colombia: 1903-1946. Bogotá: Ed. Colciencias, Foro Nacional por Colombia, U. de Antioquia, 1997. v. 2.

SALDARRIAGA, O.; SÁENZ, J. La construcción escolar de la infancia: pedagogía, raza y moral en Colombia, siglos XVI-XX. In: RODRÍGUEZ, P.; MANNARELLI, M. E. (Coords.). Historia de la Infancia en América Latina. Bogotá: Universidad Externado de Colombia, 2007.

\section{FUENTES}

CARDONA, A. Disciplina escolar. Tesis - Escuela Normal Superior de Medellín, 1939.

EDUCACIÓN Nueva. Julio 23 de 1913. El espectador Medellín, n. 1015, año 27. (Inédito).

ESTUDIO y Trabajo. Órgano de la casa de menores. Conferencia leída en febrero de 1928. Fontidueño Bello. Eduardo Machado B., f. 191, n. 66, año VI.

ESTUDIOS Pedagógicos. Más sobre la educación cívica. Oct. 15 de 1913, Medellín, f. 68, n. 9 .

MEJÍA, M. R. La Educación Física. Tesis - Escuela Normal Superior de Medellín, 1948.

MORENO, W. et al. Base Proyecto: Recuperación de fuentes documentales para la Historia de las Prácticas pedagógicas del Cuerpo Escolarizado en la Primera Mitad del Siglo XX en Medellín. CODI. Universidad de Antioquia. (Base). VIREF. Universidad de Antioquia, 2008. 